\section{Vivências de trabalhadores da saúde em face da lógica neoliberal: um estudo da atenção básica na Colômbia e no Brasil}

\author{
Health workers' experiences in dealing with the \\ neoliberal logic: a study of primary care in \\ Colombia and Brazil
}

\author{
Vivencias de trabajadores de salud frente a \\ la lógica neoliberal: un estudio de la atención \\ básica en Colombia y en Brasil
}

Johanna Garrido-Pinzón 1

Marcia Hespanhol Bernardo 1

doi: $10.1590 / 0102-311 \times 00050716$

\section{Resumo}

A presente pesquisa visa a analisar as vivências de trabalhadores da atenção básica dos sistemas públicos de saúde da Colômbia e do Brasil, em face da lógica neoliberal. Esses dois casos ganham interesse de estudo por exemplificarem sistemas de saúde cujo surgimento se dá a partir de diretrizes opostas: o sistema colombiano, criado nas esferas governamentais com uma marcada influência privatista, e o sistema brasileiro, uma importante conquista dos movimentos sociais. Baseada no enfoque da Psicologia Social do Trabalho, esta pesquisa é de natureza qualitativa e de tipo empirico. Desenvolveu-se mediante entrevistas reflexivas em profundidade, com dois grupos de trabalhadores da atenção básica de nível assistencial e administrativo: um em Bucaramanga, Colômbia, e outro, em Campinas (São Paulo), Brasil. Para o processo de análise, elegeu-se utilizar a Análise de Conteúdo. A pesquisa revelou que, em ambos os países, as principais vivências dos profissionais da saúde estão relacionadas com as transformações introduzidas nas condições, relações e organização do trabalho. No contexto colombiano, identificamos as problemáticas centrais no processo de transição induzido pela reforma que constituiu seu atual sistema de saúde. Essas problemáticas traduzem-se na deterioração das relações com os usuários, bem como na configuração das equipes de trabalho, marcadas pelo contraste entre pessoas com diferentes vinculos empregatícios. Esta última condição também é observada no contexto brasileiro, como produto da terceirização, que parece ter se tornado um efetivo mecanismo para enfraquecer o Sistea Único de Saúde (SUS), facilitar seu desmonte e colocá-lo no mesmo caminho atualmente percorrido pelo sistema colombiano.

\author{
Correspondência \\ J. Garrido-Pinzón \\ Rua Treze de Maio 1243, São Carlos, SP 13560-647, Brasil. \\ johannagarrido28@gmail.com \\ 1 Pontifícia Universidade Católica de Campinas, Campinas, \\ Brasil.
}




\section{Introdução}

\section{Caraterísticas do trabalho público da saúde no contexto neoliberal}

O presente artigo surge de uma pesquisa que teve como propósito estudar as vivências de trabalhadores da atenção básica dos sistemas públicos de saúde da Colômbia e do Brasil, em face da lógica neoliberal, considerando que esses dois casos ganham interesse de estudo por exemplificarem sistemas de saúde cujo surgimento se dá a partir de diretrizes opostas: o sistema colombiano, criado nas esferas governamentais com uma marcada influência privatista, e o sistema brasileiro, uma importante conquista dos movimentos sociais. Do mesmo modo, parte-se da premissa de que, na atualidade, o setor público, bem como o setor privado, tem experimentado as diversas transformações do mundo do trabalho.

Tradicionalmente, os serviços de saúde pública caracterizaram-se por reunir profissões e disciplinas fundamentadas em critérios éticos e de valor social. Além disso, fatores como a estabilidade e a solidez, conferidas nos estatutos de permanência dos funcionários e na tradição cultural, outorgavam aos trabalhadores desse setor certo nível de independência e liberdade no exercício de suas atividades, o que contrasta significativamente com as diretrizes empresariais e as pressões do mercado 1. No entanto, as mudanças do contexto capitalista atual têm repercutido significativamente no setor público, que, agora imerso no espírito "flexível" do capitalismo, permite que as leis do mercado controlem e regulem seu funcionamento. Nesse contexto, foram introduzidas novas formas de relações de trabalho, que promoveram a intensificação dos processos laborais, não só nas indústrias, mas em todos os setores da sociedade, inclusive nos serviços públicos de saúde 1,2,3.

É possível afirmar que as características dos modelos de gerenciamento flexível têm sido introduzidas no setor público nas últimas décadas em diversos países, determinando os dispositivos de regulação social das relações de trabalho em função da lógica da economia de mercado, sem levar em consideração a qualidade dos serviços prestados e a saúde dos trabalhadores. Tal processo foi denominado por Blanch-Ribas \& Cantera 1 como "capitalismo organizacional”. Nesse contexto, os funcionários públicos passam a ser submetidos a uma nova forma de organização do trabalho muito similar à do setor privado, com aumento da carga e do ritmo de trabalho, o qual é medido pela quantidade de serviços prestados. Em meio a esse quadro de intensificação e redirecionamento do sentido do trabalho, aparecem tensões psicossociais em nível individual e institucional 2. Particularmente no setor público da saúde, essas tensões psicossociais vêm sendo abordadas em diversas pesquisas na América Latina 4,5,6 - cujos sistemas públicos têm experimentado reformas neoliberais -, as quais evidenciam determinadas consequências para trabalhadores do setor da saúde pública, ainda que se resguardem as especificidades de cada país.

Entretanto, devemos também considerar que existem referências na América Latina de sistemas de saúde erigidos sob interesses majoritariamente sociais, os quais podem fornecer cenários alternativos no contexto das relações de trabalho. Olhando nessa direção, encontramos os casos de Cuba e do Brasil, com histórias que se desenvolveram seguindo parâmetros diferentes dos da grande maioria dos países irmãos. Esse contraste de histórias pode ser uma fonte importante de aprendizado no entendimento das experiências dos trabalhadores, mostrando-se particularmente interessante a análise dos sistemas de saúde desses dois países, tendo em vista que constituem modelos aparentemente antagônicos, concebidos no meio da mesma crise capitalista. Por um lado, tem-se a Colômbia que, dentre os países latino-americanos a sofrer a intensa crise econômica da década de 1980, foi aquele que incorporou de maneira mais rigorosa e sistemática os critérios centrais do modelo hegemônico das reformas sanitárias estabelecidos pelo Banco Mundial (BM) e pelo Fundo Monetário Internacional (FMI) 7. Por outro, observa-se a situação do Brasil, que, apesar de também ter experimentado a crise econômica, criou o Sistema Único de Saúde (SUS), produto das exigências dos movimentos populares, os quais conseguiram estabelecer a saúde como um direito de todos os cidadãos, legitimando-o na Constituição Federal de 1988 8.

No entanto, embora o SUS apoie-se desde sua origem em políticas sociais, ao longo de sua história, tem permitido a incorporação de elementos neoliberais em sua estrutura 8 . Tal constatação leva à seguinte indagação: Será que esses elementos inserem o presente e o futuro do sistema de saúde brasileiro no mesmo caminho que está percorrendo a saúde pública da maioria dos países da América Latina? 
De fato, algumas das consequências negativas que o neoliberalismo tem trazido para a saúde dos trabalhadores desse setor já foram identificadas em várias partes do território brasileiro $9,10,11$ : instabilidade do vínculo laboral e baixo salário, sensação de mal-estar com relação ao trabalho ${ }^{9}$, dificuldade para realizar adequadamente as funções, terceirização e precariedade associada à iminência do desemprego 11, aumento do ritmo de trabalho, esgotamento físico e mental, depressão, fadiga, irritabilidade, estresse 10, entre outros aspectos que são observados tipicamente nas empresas capitalistas e que também estão presentes nas instituições públicas da maioria dos outros países irmãos.

Vale esclarecer que uma das ocupações que tem definido o trajeto principal da atual pesquisa está relacionada ao pressuposto de que o conhecimento das vivências dos servidores públicos da saúde, nos dois contextos, poderia ajudar cada uma das partes a melhorar a compreensão de sua própria realidade e, provavelmente, definir novas perspectivas para lidar com os efeitos negativos da precarização e da flexibilização laboral.

Com esse intuito, toma corpo o estudo aqui apresentado, que teve como objetivo principal compreender as vivências de trabalhadores da atenção básica dos sistemas públicos da Colômbia e do Brasil em face da inserção da lógica neoliberal na organização do trabalho. É importante esclarecer também que, apesar de a organização dos serviços de saúde nos dois grupos ser constituída de forma descentralizada, dividida por níveis de atenção, na atualidade, nos níveis de atenção básica, as concepções de atenção primária variam nos dois sistemas - mais universalista no Brasil e focalizada na Colômbia -, produto das particularidades da história política de saúde nos dois países.

Deve-se lembrar que, nas décadas de 1980 e 1990, a concepção de atenção primária seletiva predominou nos processos de reforma dos sistemas de saúde na maior parte da América Latina ${ }^{12}$, incluindo a Colômbia. Já, no Brasil, o modelo de atenção primária com enfoque mais universalista, referendado na Conferência de Alma-Ata, tornou-se a base para sua reforma sanitária.

Considerando essas características, antes de discutir as vivências dos trabalhadores da atenção básica nesses dois países, é importante compreender alguns outros fenômenos relevantes que permitem a compreensão de suas tradições.

\section{As distintas reformas e suas implicações para os trabalhadores da saúde}

Após a aprovação da Lei no 100, em 1993, o novo sistema de saúde colombiano incorpora os delineamentos básicos das políticas neoliberais, que levam ao enfraquecimento do papel do Estado como provedor de serviços sociais e à privatização das empresas públicas 13 . Trata-se de um sistema misto, no qual o Estado assume um papel diretor e modulador, mas libera-se das responsabilidades de cobertura securitária e prestação de serviços, que passam a ser assumidas dentro de um esquema competitivo, por instituições públicas e privadas, com e sem objetivo de lucro ${ }^{13}$. Nesse sistema, coexistem dois regimes criados: o contributivo e o subsidiado. Na organização do regime subsidiado, não existe uma distribuição dos usuários por centro de atenção básica, sendo a escolha da unidade livre.

No mundo do trabalho na Colômbia, a característica principal, desde a década de 1990, é a implantação de reformas laborais regressivas, cujo propósito é a eliminação progressiva das garantias conquistadas no passado pelos trabalhadores e a diminuição dos custos com a força de trabalho. Para tanto, agem na legitimação de práticas de desregulação, flexibilização e precariedade laboral. Pode-se dizer que, na Colômbia, os processos de flexibilização adotados mudaram significativamente o contexto do trabalho no campo da saúde, junto com o modelo da competição regulada. Esses processos estão corporificados nas leis no 50, de 1990 (reformas ao Código Substantivo do Trabalho); no 100, de 1993 (em que se cria o Sistema Geral de Seguridade Social em Saúde - SGSSS); e no 789, de 2002 (conhecida como a reforma laboral). Em decorrência, vão despontando novos protagonistas intermediários ligados à terceirização da força de trabalho, conformando distintas maneiras de contratação que perpetuam, por assim dizer, as práticas emergentes da doutrina neoliberal 7: cooperativas de trabalho associado, agências de trabalho temporário e contratos de prestação de serviços, bem como o congelamento das folhas de pagamento de trabalhadores concursados no setor público.

Por outra parte, a experiência da reforma da saúde brasileira tem peculiaridades que a diferenciam do contexto predominante na América Latina. A saúde no Brasil figura como um direito de todos os cidadãos, conforme está assegurado na Constituição Federal de 1988, graças à influência exercida pelo Movimento Sanitário e pelo Movimento Popular de Saúde, cujo objetivo principal era a criação 
do SUS 8, o qual foi regulamentado pela Lei no 8.080/1990. No embate político da Constituinte, no entanto, acabou sendo aprovado um sistema público que abria uma brecha para a "participação" do privado. Contraditoriamente, o mesmo Estado que constituiu o SUS como um projeto de medicina socializada (avesso ao projeto neoliberal) possibilita a lógica neoliberal dentro do setor da saúde. Consequentemente, algumas das implicações práticas são experimentadas no interior do SUS, tanto em sua estrutura administrativa, como em seu modelo assistencial. Por exemplo, detecta-se o constante subfinanciamento do sistema, que limita sua capacidade de investimento na ampliação da cobertura assistencial, degradando as estruturas públicas e impedindo a melhora da gestão dos serviços, para, assim, justificar sua privatização 14 .

Nos últimos anos, observa-se também a entrada mais acentuada de entidades privadas na gestão de serviços de saúde 14. Evidencia-se, portanto, uma significativa inserção de processos de terceirização do gerenciamento do SUS com organizações sociais em distintos estados e municípios do Brasil. Esse tipo de ação insere o sistema em um processo de privatização, uma vez que atua na desvinculação da força de trabalho da estrutura do sistema de saúde.

No âmbito da atenção básica, o sistema também vem sofrendo mudanças, passando do modelo baseado em centros de saúde para a Estratégia Saúde da Família (ESF). Essa mudança de foco tem sido alvo de muito debate, sendo criticada por alguns como uma política que tira o caráter universal da atenção básica, assumindo uma característica mais focal. Tal configuração também muda as características das equipes da atenção básica, que ficam mais centradas no médico generalista e na equipe de enfermagem 15 .

\section{O percurso metodológico}

Esta pesquisa é de natureza qualitativa e de tipo empírico, tendo se desenvolvido mediante a realização de entrevistas reflexivas em profundidade 16, com dois grupos de trabalhadores de diversas categorias profissionais que compõem a atenção básica, sendo um em Campinas, São Paulo, Brasil, e outro, em Bucaramanga, Colômbia. Essas entrevistas foram realizadas durante os anos de 2014 e 2015 com trabalhadores de diferentes Centros de Atenção Básica nas duas cidades, sendo 11 em Bucaramanga, e seis em Campinas. Essas cidades foram escolhidas, considerando-se suas similaridades sociogeográficas e sua importância histórica na constituição dos sistemas de saúde em cada um dos países.

A região metropolitana de Bucaramanga, localizada no nordeste da Colômbia, tem uma população estimada em 1.122.961 habitantes no ano de 2015, segundo o Departamento Administrativo Nacional de Estadística (DANE). Atualmente, existem 30 unidades pertencentes ao regime subsidiado, que possibilitam o acesso aos serviços de atenção primária em saúde para a população mais vulnerável. Historicamente, Bucaramanga foi uma cidade que, antes da Lei no 100, tinha adotado um modelo de atenção básica fortemente baseado nos princípios de Alma Ata e, assim, sofreu forte impacto com a mudança no sistema.

Por outra parte, de acordo com dados disponibilizados pelo Instituto Brasileiro de Geografia e Estatística (IBGE) para o ano 2015, o Município de Campinas, situado no interior de São Paulo, na Região Sudeste do Brasil, possui uma população estimada em 1.164.098 habitantes. Segundo a Prefeitura de Campinas, o município possui 61 unidades básicas de saúde (UBS), tendo adotado o modelo da ESF com adaptações à estrutura já existente. Assim, em uma mesma unidade de atenção básica, convivem diversas equipes responsáveis pela população de territórios específicos. Na história, Campinas é reconhecida como um município onde os princípios e a estrutura do SUS foram aplicados de forma mais abrangente.

Os sujeitos da pesquisa incluem-se nas seguintes categorias profissionais: auxiliares de enfermagem, médicos, enfermeiros e psicóloga, além de trabalhadores da área administrativa - estes últimos participantes só no contexto colombiano. Essa escolha de inclusão dos diferentes profissionais da atenção básica deu-se, visando a incluir categorias variadas de trabalhadores, com visões e perspectivas diversas sobre a organização do trabalho na atenção básica, bem como a ter acesso a diferentes vivências que representassem a dinâmica do contexto de trabalho público atual nesse nível, em particular.

Nessa empreitada, deparamos com participantes cujas vivências eram diversificadas e significativas, que aportaram informações relevantes para os interesses da pesquisa. Por exemplo, o fato de 
que, na Colômbia, existem trabalhadores administrativos com papel decisivo na forma como o atendimento é oferecido à população - auditores com poder de veto a exames solicitados por médicos, por exemplo - fez com que fosse importante a participação desses profissionais no estudo. Contamos também com a participação de trabalhadores e ex-trabalhadores da atenção básica que vivenciaram experiências significativas relacionadas a momentos históricos decisivos do setor da saúde, que refletem as diversas mudanças ocasionadas na organização do trabalho de ambos os países. Igualmente, em Campinas, buscamos abranger trabalhadores da atenção básica pertencentes às equipes da ESF, bem como procuramos incluir trabalhadores concursados e terceirizados com o intuito de que pudessem compartilhar experiências singulares, que representassem os diferentes matizes presentes atualmente nesse contexto de trabalho.

As entrevistas foram gravadas com prévia autorização dos participantes e, depois, transcritas. O material obtido foi submetido à análise de conteúdo 17 , com o intuito de identificar as categorias que aludissem aos objetivos da pesquisa.

\section{Considerações éticas}

Foram obtidos os consentimentos informados dos participantes, expondo os objetivos da pesquisa e garantindo o anonimato dos sujeitos na divulgação dos resultados, a liberdade para retirada do consentimento a qualquer momento e a informação quanto ao destino das informações produzidas.

Este estudo foi aprovado pelo Comitê de Ética em Pesquisa da Instituição de Ensino Superior à qual as autoras são filiadas, sob o parecer no 495.238, em 16 de dezembro de 2013.

\section{Colômbia e Brasil: implicações da lógica neoliberal na vivência de trabalhadoresda saúde pública}

Na síntese interpretativa das entrevistas, surgiram diversos temas. Neste artigo, serão apresentados especificamente dois deles, que se referem às vivências dos trabalhadores no processo de reforma de seus correspondentes sistemas de saúde: (a) as mudanças na atenção básica; e (b) as dificuldades de coesão dos grupos de trabalho com diferentes vínculos.

Vale esclarecer que decidimos manter no idioma original, o espanhol, os trechos das falas dos entrevistados colombianos, a fim de não alterar o significado de seu discurso.

\section{As mudanças na atenção básica}

Segundo os entrevistados, o sistema de saúde colombiano é marcado pela perda de valores e se distancia dos princípios estipulados nas leis. Os mais antigos lembram que nem sempre foi assim. Na década de 1980 - portanto, antes da implantação do atual sistema de saúde - os princípios da atenção primária à saúde de Alma-Ata chegaram a ser aplicados na Colômbia. A organização do trabalho da atenção básica possibilitava que os profissionais desenvolvessem suas atividades sob uma lógica diferente da atual, com autonomia e vínculo entre equipe de saúde e usuários, focalizando o cuidado da saúde da população com base nas propostas originais da atenção primária à saúde.

A esse respeito, destacam-se as vivências relatadas pelos médicos. Pablo, que trabalhava na atenção básica naquela época - atualmente atua na área administrativa desse nível -, lembra que, antes da Lei no 100, Bucaramanga havia tido excelentes experiências no primeiro nível de atenção, e ressalta com nostalgia como as relações com a comunidade, com os colegas e com o trabalho tinham outros sentidos:

"Nosotros fuimos pioneros, Bucaramanga junto con Cali, éramos referencia en el modelo de atención primaria. Antes de la Ley 100, teníamos un modelo para la atención primaria y contábamos con unos programa (...) También existía el segundo y tercer nivel, pero lo que predominaba en Colombia era el primer nivel, eran los centros y puestos de salud (...) Realizábamos un gran trabajo extra mural, entonces haciamos las brigadas, salíamos, participábamos, en fin... Lo cierto es que sí había una gran relación con la comunidad y un trabajo como Dios manda, coherente con lo que decía en ese momento la constitución colombiana y la normatividad que predominaba en ese momento". 
Ele ainda ressalta como, na lógica anterior, prevalecia a relação profissional-usuário, a ativa participação dos profissionais na comunidade, o forte vínculo estabelecido, bem como o amplo conhecimento que a equipe tinha da população:

"Antes, sí era un buen momento, pues era posible realizar atención primaria, al punto que podiamos participar con las comunidades de todos los programas de atención básica. (...) Habia una atención primaria con programas reales, con un voluntariado, o sea con un vínculo real con la comunidad. Podíamos hacer visitas domiciliarias y sabíamos quien estaba embarazada, quien tuvo un ACV, quien se enfermó durante la noche (...) Mis voluntarios, nuestro equipo sabía todo lo que sucedía en la comuna y no era una comuna pequeña, era una comuna significativa respecto a población".

Um dos aspectos mais destacados pelos entrevistados com relação à adoção do novo sistema colombiano, centrado no cliente e em sua capacidade de pagamento 7 , diz respeito às distintas restrições à autonomia profissional, em especial no que tange à atividade médica, impostas pela atual lógica economicista. Praticamente todos os participantes ressaltam que as equipes de profissionais de saúde são avaliadas segundo esse parâmetro empresarial - auditorias financeiras que avaliam o trabalho em termos de produtividade e custos. O médico é tomado como um organizador do gasto econômico e, como tal, deve empreender ações para poupar recursos. Assim se expressa Jaime, médico com experiência de 27 anos na atenção básica:

"El médico se siente muy limitado, en cuantas formulas da, en cuantos exámenes da, porque cambió la toma decisiones. Ya no es el medico como tal, ahora son las Empresas Promotoras de Salud o Administradoras del Regimen Subsidiado, que son dirigidas por un gerente, y generalmente, el gerente cambió el concepto de bienestar social por el de empresa. Entonces, al cambiar las prioridades para favorecer los intereses de las empresas, su principal objetivo, siempre será el factor económico. Antes de la ley 100, la prioridad era generar salud".

Entre todas as categorias de trabalhadores da atenção básica na Colômbia, podemos considerar que os médicos são aqueles que sofrem maiores pressões no cotidiano, visto que não gozam de plena liberdade para o exercício de sua profissão, com condições para cumprir fielmente os parâmetros da ética profissional tradicional. É importante esclarecer que o modelo atual do sistema outorga ao médico um maior protagonismo, sendo colocado no centro da tomada de decisões sobre a saúde dos usuários. Já a participação dos outros profissionais limita-se a auxiliá-lo em atividades próprias de cada cargo.

Apesar de o sistema colombiano de cunho privatista já estar consolidado há muito tempo, alguns participantes da pesquisa originários desse país demonstram uma reflexão bastante crítica sobre as consequências desse contexto. Ainda que alguns deles não tenham vivenciado o trabalho na saúde antes da implantação do atual sistema, os dados históricos e o contexto macrossocial em que a transição se deu são lembrados por quase todos para destacar que a mudança trouxe prejuízos para a população e para os trabalhadores. Nesse sentido, consideram que a sociedade e o Estado colombiano aderem muito facilmente a essa situação e até mesmo a estimulam. Pablo é um dos entrevistados que apresenta o discurso mais crítico ao sistema, respaldado por sua trajetória, conhecimento, experiência e inserção política na história da atenção básica de Bucaramanga. Ao ser indagado sobre as fortes mudanças que sofreu o setor da saúde e, em especial, o nível da atenção básica, responde:

"El Estado sacrificó 60 mil personas en Colombia por un préstamo al Banco Interamericano de Desarrollo. Se inventó un cuento de liquidación, de reorganización, de restructuración, ipura paja! porque ahí no se reorganizó nada, porque todo quedo igual, con la diferencia que lo que hicimos fue no formalizar los trabajos, una vez despedidos, una vez indemnizados (...) Eso era innecesario, era innecesario reducir el Estado colombiano a expensas de la salud. Yo a veces creo que eso era algo así como un rito medio satánico, de unos señores llamados Neoliberales, que dijeron que teníamos que sacrificarnos, porque parece que tenían un dios que habia que ofrecerle sacrificios".

Pode-se dizer, então, que as mudanças determinantes sofridas pelos serviços de atenção básica na Colômbia propiciaram vivências significativas, em especial, para aqueles trabalhadores que acompanharam esse percurso histórico, desde antes da reforma de saúde, quando seus interesses de caráter social se aproximavam dos postulados de Alma-Ata, até o período posterior à reforma, de consolidação do modelo atual.

O quadro descrito contrasta com o processo que vem experimentando o campo da saúde pública no Brasil, especificamente com seu modelo de atenção primária à saúde, o qual, até o momento, mantém seu status de estratégia principal do primeiro nível de atenção. Não obstante, de acordo com o que 
sabemos sobre a trajetória do SUS até o presente - sobre sua tendência ao desmonte 8 -, é possível que, em um futuro próximo, os trabalhadores vivenciem vários elementos que permeiam o cenário colombiano, como os apresentados anteriormente.

Apesar de Campinas possuir certa tradição no campo da saúde, que faz dela referência no Brasil, seu sistema de saúde, assim como o restante do país, aos poucos, está experimentando uma série de ações que concorrem para seu desmonte, como a Lei Complementar no 101/2015, denominada de Lei das Organizações Sociais, recentemente aprovada pela Câmara Municipal, que fornece base legal para a retomada da contratação terceirizada no setor público, permitindo sua gestão por Organizações Sociais. Nesse sentido, Fabiano, médico da atenção básica, que tem um histórico de militância no SUS, assinala criticamente algumas dessas ações, como a sobrecarga atual de população por equipe de trabalho e a carência de um direcionamento sistemático dos programas, que faz com que eles dependam totalmente da gestão política do momento.

"Campinas tem uma sobrecarga muito grande no sentido do tamanho da população que cada equipe [da saúde da família] é responsável. É humanamente impossivel dar conta daquilo que é o seu trabalho (...) Mas eu sei que a gente não tem condições objetivas de garantir o direito da saúde, pois a gente tem uma quantidade, um tamanho da população para dar conta, que é muito além do que é razoável. Isso é dado oficial de Campinas. O município tem em média oito mil pessoas por equipe de saúde da família e a portaria do Ministério da Saúde, que aliás, não é nenhuma maravilha, fala de duas a quatro mil pessoas... A gente já está duplicando o limite máximo, viu? (...) Então, para mim, é muito claro que tem um processo de desmonte mesmo, de não se saber para onde vai e o que se quer (...) Ninguém sabe para onde vai o SUS de Campinas... Faz tempo já, há dez anos que eu estou aqui e não tem uma coisa assim de projeto mesmo...."

Assim, parece que a carência de recursos para uma atenção adequada à população tem levado Campinas a percorrer um caminho que, aos poucos, pode aproximá-la da realidade de Bucaramanga. No entanto, por se tratar de duas experiências que têm trilhado histórias distintas, as formas como se produzem essas consequências mantêm características singulares. Uma delas tem a ver com o fato de que, embora a demanda da população em Campinas ultrapasse o limite de atendimento de usuários por equipe de trabalho na atenção básica, os profissionais da saúde ainda parecem gozar de autonomia e alguma liberdade para definir suas prioridades. Por exemplo, algumas equipes ainda podem priorizar os programas de promoção de saúde e prevenção, mediante um trabalho organizado, coordenado e participativo dos integrantes da equipe. Rafael, enfermeiro efetivo que exerce o cargo de cogestor de sua unidade básica, explicita como é realizada a organização da agenda de trabalho, considerando a alta demanda de população a ser atendida:

"A gente tem que se adequar à realidade. Não adianta eu causar um sofrimento para minha equipe, porque eu não tenho uma quantidade de profissionais para atender a densidade demográfica da população local, né? Eu não tenho! Então, o que a gente tem que fazer, tem que organizar nossa agenda de forma que priorize as pessoas que são mais vulneráveis, entendeu? Eu tenho que garantir a agenda para criança de até dois anos, eu tenho que garantir agenda para gestante, para o paciente com diabetes e hipertensão. E, assim, a gente faz".

Devido à forma como está configurado o sistema colombiano - caracterizado pelas fortes restrições que fazem parte de sua normatividade -, torna-se complexo empreender modos alternativos de atenção à população, como aqueles referidos nos relatos de participantes de Campinas. O controle excessivo que se dá sobre o trabalhador na Colômbia parece ainda não ter chegado aos profissionais da atenção básica de Campinas. A seguinte fala do médico Fabiano mostra como ele ainda consegue ser fiel aos critérios éticos e clínicos no desempenho das suas atividades de trabalho:

"Eu, felizmente, tenho a senha, tenho o meu computador na sala, controlo a agenda do meu jeito. Marco a dona Maria separada do marido dela, porque eu sei que não dá para ver os dois juntos. Então, assim, tem um controle ali que é muito saudável, que a gente tenha, né?".

Outro aspecto a ser destacado, por contrapor-se ao caso de Bucaramanga, refere-se ao fato de que, em Campinas, ainda existe a ideia de equipe de trabalho, o que pode aliviar a pressão associada ao protagonismo do médico, mesmo que a ESF o coloque no centro. A constituição desse ambiente de trabalho em equipe, por sua vez, favorece o atendimento integral à comunidade, tal como é observado na fala de Fabiano, quando apresenta uma estratégia conformada por sua equipe para acolher mais pessoas e fornecer um atendimento integral:

"Esse grupo das quartas-feiras é uma estratégia para falar, inclusive: 'olha, qualquer problema de saúde de vocês, a gente está aqui para ajudar, seja na hora da urgência, ter o pronto socorro, a queixa aguda, vai direto 
lá, no posto' (...) É tentar fazer uma abordagem integral e tentar com que as pessoas reconheçam e entendam que a gente está ali para ajudar com a saúde, como um todo (...) Acredito que o jeito dos grupos das quartas-feiras é uma forma para conseguir não só atender mais pessoas, senão, também, atendê-las de forma integral!”.

Conceber um antes e um depois nas histórias da atenção básica dos dois sistemas de saúde resulta muito mais visível na Colômbia do que no Brasil, uma vez que este último ainda está no meio de um processo de fragmentação já vivenciado pelo primeiro. Ainda que o contexto brasileiro pesquisado tenha suas problemáticas peculiares, relacionadas, principalmente, ao número excessivo de população sob responsabilidade de cada UBS, ele ainda conserva características que permitem certo alívio do sofrimento envolvido nas diversas formas de precariedade, e esse efeito se desdobra, por conseguinte, no funcionamento e na qualidade dos serviços oferecidos a seus usuários.

\section{Dificuldades de coesão dos grupos de trabalhadores com diferentes vínculos}

No caso da Colômbia, cabe lembrar que o fenômeno da terceirização está radicalmente consolidado no setor da saúde pública, desde a implantação das reformas laborais do país. No campo da organização do trabalho, distinguem-se as condições objetivas, visivelmente marcadas entre trabalhadores "concursados" e "terceirizados", as quais abarcam todas as categorias dos profissionais, mas que foram especialmente destacadas nas falas das profissionais de enfermagem entrevistadas. A esse respeito, no relato de Pilar, auxiliar de enfermagem terceirizada, observam-se algumas dessas diferenças que perpassam o tipo de contrato laboral, tais como salários, benefícios trabalhistas (ou sua perda, no caso dos temporários), cargas horárias e escalas de trabalho, assim como as relações com a equipe de trabalho e o conteúdo de trabalho a desempenhar dentro das mesmas funções:

"Nosotras las temporales trabajamos 48 horas semanales, las de planta [concursadas] trabajan 40 horas. Nosotras tenemos cuatro turnos por semana de doce horas diarias, de lunes a domingo, descansando sólo un día a la semana. Trabajamos un sábado o domingo, igual como si fuera un día de la semana cualquiera. No nos pagan horas extras, ni dominicales, ni festivos. En cambio las de planta si tienen descanso los sábados y los domingos. Ellas trabajan de lunes a viernes, desde las 7:00 a.m. hasta las 3:00 p.m. (...) Nosotras solo ganamos un salario mínimo, ellas nos triplican el salario, ¿si ve? Y hacemos exactamente lo mismo, inclusive más, porque nosotras trabajamos todos los días de 7:00 a.m. a 7:00 p.m. (...)".

No mesmo sentido, Sara, também auxiliar de enfermagem terceirizada, é direta ao assinalar a existência de uma diferença hierárquica "encoberta" entre trabalhadoras que exercem os mesmos cargos, porém com tipos de contrato diversos. Ela expressa como essa circunstância provoca - tanto nela como em outros colegas sob a mesma condição - uma série de situações constrangedoras no local de trabalho, bem como tece uma relação de "subordinação" intrínseca entre colegas que exercem as mesmas funções.

"Yo soy de contrato y veo que dentro de un mismo cargo se tiene una jerarquía que no está escrita. Por ejemplo, la jefe lo piensa dos veces antes de mandar a alguna auxiliar de planta. Inclusive, la jefe también es de contrato, por cooperativa (...) A veces, las de planta hacen lo mínimo en el trabajo, porque saben que nadie les va a decir nada”.

Em Campinas, bem como em grande parte do país, o fenômeno da terceirização no setor da saúde pública não se encontra tão distante do cenário colombiano. Convém, todavia, pontuar que, se atualmente a contratação dos trabalhadores da saúde em Campinas é feita integralmente por meio de concurso público, provavelmente isso não permanecerá por muito tempo. Além do cenário nacional desfavorável para políticas públicas universais, a Lei no 101/2015, já citada acima, possibilita não apenas as contratações de trabalhadores por terceiros, mas também retira qualquer empecilho para que a própria administração dos serviços públicos seja terceirizada. Nesse sentido, Rafael, enfermeiro concursado, anota como a incursão da terceirização no setor público prejudica notavelmente o exercício da autonomia na execução do trabalho:

"A gente tem mais margem de negociação, por exemplo, eu posso negociar com a minha gestora local hoje, porque a gente é servidor público (...) Consigo aqui, porque a gente tem um vínculo que é público. Se eu trabalhasse em uma unidade que é terceirizada, nem poderia. Minha gestora falaria: 'Rafael, eu concordo com você, mas não pode, porque seu contrato é esse e tal...”.

Antes de finalizar, é importante destacar que, no Brasil, nas últimas duas décadas, a terceirização alastrou-se de forma generalizada em todos os setores, especialmente no público e nas empresas 
estatais, sob a modalidade de cooperativas, sobretudo na área da saúde, e com a externalização de serviços públicos, da administração direta para empresas privadas 18 . Particularmente com relação aos serviços de saúde, é possível testemunhar a presença bastante intensa desse fenômeno em diversos municípios brasileiros, nos quais se configura uma realidade muito mais próxima à da Colômbia.

\section{Considerações finais}

As principais consequências que a lógica neoliberal tem acarretado para as vivências dos trabalhadores da saúde pública em ambos os países estão relacionadas às mudanças introduzidas nas condições, relações e organização do trabalho, cujo impacto se sente nas duas dimensões envolvidas no processo de trabalho: os trabalhadores e o serviço prestado aos usuários.

No cenário de Bucaramanga, que apresenta uma marcada transição no modelo da atenção básica, resultante da reforma introduzida em 1993, as consequências sobre os trabalhadores traduzem-se na perda de autonomia profissional, na instauração da terceirização, que leva a uma intensa precarização do trabalho no setor e, consequentemente, à falta de união no interior das equipes de trabalho, bem como à reconfiguração nas relações com os usuários. Essas duas últimas características surgem do distanciamento do modelo da atenção primária à saúde, que tem minado a antiga coordenação e cooperação entre os diversos profissionais da equipe, perdendo, simultaneamente, a proximidade com a comunidade.

Por outro lado, no contexto de Campinas, apesar de ter conservado, desde a promulgação da Constituição Federal, uma estratégia de atenção básica próxima aos preceitos da atenção primária à saúde, pode-se identificar, na atualidade, um conjunto de ações que concorre para o desmonte do seu sistema público de saúde, como o excesso de demandas para as equipes de trabalho, a falta de um direcionamento sistemático dos programas - o que faz com que o sistema dependa, de certa maneira, da gestão política do momento - e a incursão da terceirização, que sugere uma transição similar à observada na Colômbia, mesmo que mais lenta. No caso brasileiro, o fato de se ter mantido o modelo inicial de atenção básica tem viabilizado a conservação da autonomia, da cooperação e da coordenação dos profissionais em algumas equipes de trabalho, mesmo no caso dos médicos que, como na Colômbia, realizam atividades centrais no primeiro nível de atenção. Esse ambiente de trabalho cooperativo em equipe, por sua vez, favorece o atendimento integral à comunidade, bem como um relacionamento mais próximo com os usuários.

Diante desse panorama de precariedade social ${ }^{19}$, nesta pesquisa, emergiram distintos questionamentos suscetíveis de serem aprofundados em futuros estudos, tais como o impacto de tal contexto na subjetividade do trabalhador, na sua relação com o trabalho, nos âmbitos pessoal e familiar e na sua saúde física e mental. Igualmente, seria conveniente indagar sobre as distintas formas de enfrentamento e de resistência adotadas pelos profissionais, em seu cotidiano de trabalho.

Contudo, pode-se dizer que, neste estudo, a experiência do sistema de saúde colombiano foi considerada uma referência para a análise das repercussões da ideologia neoliberal nos trabalhadores do SUS, sendo este tipo de conhecimento, para os brasileiros, um recurso importante que ajuda a avaliar criticamente onde o Brasil poderia chegar, especialmente considerando o cenário atual.

\section{Colaboradores}

J. Garrido-Pinzón M. H. Bernardo participaram, igualmente, das etapas de concepção, redação e revisão final do artigo.

\section{Agradecimentos}

O desenvolvimento da pesquisa que originou o artigo contou com apoio financeiro da Capes (Coordenação de Aperfeiçoamento de Pessoal de Nível Superior). 


\section{Referências}

1. Blanch-Ribas JM, Cantera L. La nueva gestión pública de universidades y hospitales: Aplicaciones e implicaciones. In: Agulló ET, Âlvaro JL, Garrido AL, Medina R, Schweiger IG, editores. Nuevas formas de organización del trabajo y la empleabilidad. Oviedo: Universidad de Oviedo; 2011. p. 515-34.

2. Gaulejac V. Gestão como doença social. Aparecida: Ideias e Letras; 2007.

3. Linhart D. Modernisation et précarisation de la vie au travail. Papeles del CEIC 2009; 43:1-19.

4. Abadía C, Pinilla M, Ariza K, Ruíz H. Neoliberalismo en salud: la tortura de trabajadoras y trabajadores del Instituto Materno Infantil de Bogotá. Rev Salud Pública 2012; 14:18-31.

5. Guevara EB, Mendias EP. A comparative analysis of the changes in nursing practice related to health sector reform in five countries of the Americas. Rev Panam Salud Pública 2001; 12:347-53.

6. Machado AL, Giacone M, Álvarez C, Carri P. La reforma de la salud y su impacto en los trabajadores del sector: el caso Hospital Nacional de Clínicas de Córdoba, Argentina. Medicina Social 2007; 2:17-26.

7. Hernández M. El enfoque sociopolítico para el análisis de las reformas sanitarias en América Latina. Rev Salud Pública 2001; 19:57-70.

8. Campos GWS. O SUS entre a tradição dos sistemas nacionais e o modo liberal-privado para organizar o cuidado à saúde. Ciênc Saúde Coletiva 2007; 12:1865-74.

9. Bernardo MH, Verde FF, Garrido J. Vivências de trabalhadores com diferentes vínculos empregatícios em um laboratório público. Cad Psicol Soc Trab 2013; 16:119-33.
10. Gonçalves FGA, Souza NVDO, Pires AS, Dos Santos DM, D'Oliveira CAFB, Ribeiro LV. Modelo neoliberal e suas implicações para a saúde do trabalhador de enfermagem. Rev Enferm UERJ 2014; 22:519-25.

11. Verde F, Bernardo MH, Büll S. Trabalho e precarização na saúde pública. Revista ECOS 2013; 3:18-31.

12. Giovanella L. Atenção primária à saúde seletiva ou abrangente? Cad Saúde Pública 2008; 24 Suppl 1:S21-3.

13. Ahumada C. Política social y reforma de salud en Colombia. Revista Papel Político 1998; 7:9-35.

14. Borges F, Moimaz S, Siqueira CE, Garbin C. Anatomia da privatização neoliberal do Sistema Único de Saúde: o papel das organizações sociais de saúde. São Paulo: Cultura Acadêmica; 2012.

15. 'Scarcelli IR, Junqueira V. O SUS como Desafio para a Formação em Psicologia. Revista Psicologia: Ciência e Profissão 2011; 31:340-57.

16. Hammersley M, Atkinson P. Etnografía: métodos de investigación. Barcelona: Paidós; 1994.

17. Minayo MCS. Pesquisa Social: teoria, método e criatividade. Petrópolis: Editora Vozes; 1999.

18. Antunes R, Druck G. A epidemia da terceirização. In: Antunes R, organizador. Riqueza e miséria do trabalho no Brasil III. São Paulo: Boitempo; 2014. p. 13-24.

19. Franco T, Druck G, Seligmann-Silva E. As novas relações de trabalho, o desgaste mental do trabalhador e os transtornos mentais no trabalho precarizado. Rev Bras Saúde Ocup 2010; $35: 229-48$ 


\section{Abstract}

The aim of this study was to analyze the experiences of primary healthcare workers in the public health systems in Colombia and Brazil in relation to the neoliberal logic. These two cases are relevant to public health research, as examples of health systems that emerged from opposing guidelines: the Colombian system was created at the government level with a marked private-sector influence, while the Brazilian system was an important conquest by social movements. Based on the Social Psychology of Work, this was a qualitative and empirical study. In-depth reflexive interviews were conducted with two groups of primary healthcare and administrative workers: one in Bucaramanga, Colombia, and the other in Campinas (São Paulo State), Brazil. Content analysis was used in the analytical process. According to the study, in both countries the main experiences of healthcare workers involve the changes in working conditions, relations, and organization. In the Colombian context, we identified the central problems in the transition induced by the reform that established the country's current health system. These problems are expressed in the deterioration of relations with health system users, as well as in the configuration of healthcare teams, marked by conflicting employment arrangements in the healthcare staff. The latter condition also appears in the Brazilian context, as a result of outsourcing, which appears to have become an effective mechanism for undermining the Brazilian Unified National Health System (SUS), facilitating its dismantlement and pointing it in the same direction as the Colombian system.

Health Personnel; Health Care Reform; Privatization; Health Systems

\section{Resumen}

La presente investigación tiene como objetivo analizar las vivencias de trabajadores de atención básica de los sistemas públicos de salud de Colombia $y$ de Brasil, frente a la lógica neoliberal. Esos dos casos atraen el interés para su estudio por ejemplificar sistemas de salud cuyo surgimiento se da a partir de directrices opuestas: el sistema colombiano, creado en las esferas gubernamentales con una marcada influencia privatizadora, y el sistema brasileiro, una importante conquista de los movimientos sociales. Basada en el enfoque de la Psicología Social del Trabajo, esta investigación es de naturaleza cualitativa y de tipo empírico. Se desarrolló mediante entrevistas reflexivas en profundidad, con dos grupos de trabajadores de la atención básica en el nivel asistencial y administrativo: uno en Bucaramanga, Colombia, y otro, en Campinas (São Paulo), Brasil. Para el proceso de análisis, se eligió utilizar el análisis de contenido. La investigación reveló que, en ambos países, las principales vivencias de los profesionales de la salud están relacionadas con las transformaciones introducidas en las condiciones, relaciones y organización del trabajo. En el contexto colombiano, identificamos las problemáticas centrales en el proceso de transición, inducido por la reforma que constituyó su actual sistema de salud. Estas problemáticas se traducen en el deterioro de las relaciones con los usuarios, así como en la configuración de los equipos de trabajo, marcadas por el contraste entre personas con diferentes vínculos de empleo. Esta última condición también es observada en el contexto brasileño, como producto de la tercerización, que parece haberse convertido en un efectivo mecanismo para debilitar al Sistema Único de Salud (SUS), facilitar su desmantelamiento y situarlo en el mismo camino actualmente recorrido por el sistema colombiano.

Personal de Salud; Reforma de la Atención de Salud; Privatización; Sistemas de Salud

Recebido em 28/Mar/2016

Versão final reapresentada em 12/Jul/2016

Aprovado em 08/Set/2016 